\title{
Microstructural and sliding wear behaviour of a heat-treated zinc-based alloy
}

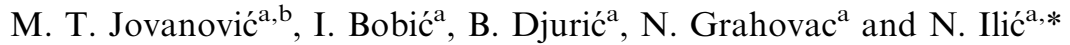 \\ ${ }^{a}$ Department of Materials Science, Institute of Nuclear Sciences "Vinča", 11001, Belgrade, Serbia and Montenegro \\ ${ }^{b}$ Stahlwerke Bremen, 28237, Bremen, Germany
}

\section{Erratum to: Tribology Letters DOI: 10.1007/ s11249-006-9106-8}

This erratum is regarding a printer's error to figure 1.

The correct figure is as follows:

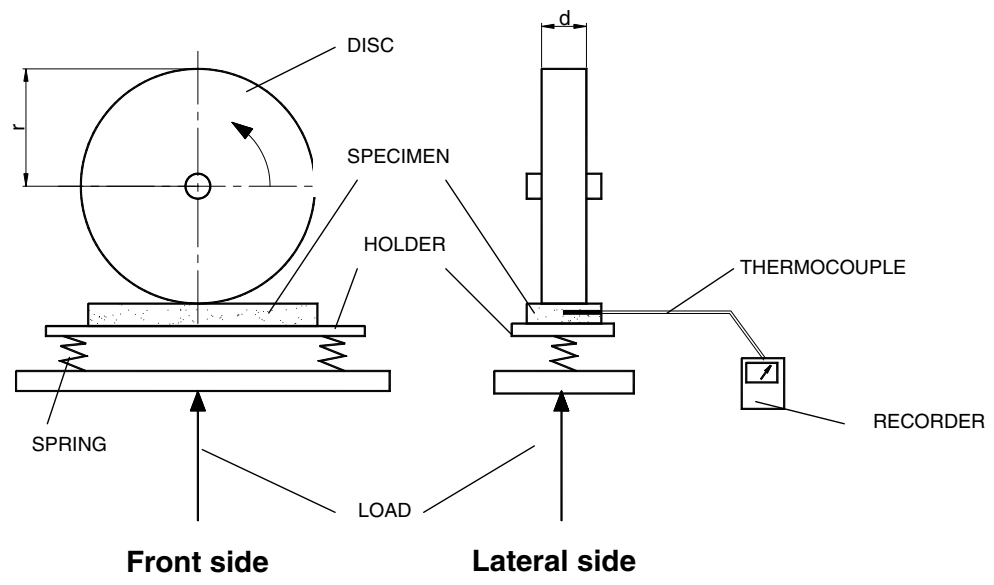

Figure 1. Schematic presentation of the disc-on block type wear test apparatus.

The online version of the original article can be found at http://

dx.doi.org/10.1007/s11249-006-9106-8

*To whom correspondence should be addressed.

E-mail: miljov@vin.bg.ac.vu 